\title{
In vivo and in vitro $\alpha$-amanitin metabolism studies using molecular networking
}

Brendan Le Daré ${ }^{1,2^{*}}$, Pierre-Jean Ferron ${ }^{1}$, Aurélien Couette $^{2}$, Catherine Ribault ${ }^{1}$, Isabelle Morel ${ }^{1,2}$, Thomas Gicquel ${ }^{1,2}$

1. Univ Rennes, INSERM, INRAE, CHU Rennes, Institut NuMeCan (Nutrition, Metabolism and Cancer), PREVITOX network, F-35033 Rennes, France.

2. Rennes University Hospital, Forensic Toxicology Laboratory, F-35033 Rennes, France.

Corresponding author: Dr. Brendan Le Daré

ORCID: 0000-0002-5907-2450

Publons: AAL-7050-2020

Address : Laboratoire de toxicologie biologique et medico-légale, CHU Pontchaillou, 2 Rue Henri Le Guilloux, 35000 Rennes.

E-mail: brendan.le.dare@chu-rennes.fr

\section{Highlights}

- The hypothesis of a possible metabolism of amanitins is still controversial in Amanita phalloides poisonings

- Differentiated hepatocyte-like HepaRG is a suitable model to study amanitin toxicity

- Using molecular networking on both in vitro and in vivo, no $\alpha$-amanitin metabolite was found

- $\alpha$-amanitin does not presumably undergo metabolism in humans

\begin{abstract}
Amanitin poisonings are among the most life-threatening mushroom poisonings, and are mainly caused by the genus Amanita. Hepatotoxicity is the hallmark of amanitins, powerful toxins contained in these mushrooms, and can require liver transplant. Among amatoxins, $\alpha$-amanitin is the most studied. However, the hypothesis of a possible metabolism of amanitins is still controversial in this pathophysiology. . Therefore, there is a need of clarification using cutting-edge tools allowing metabolism study. Molecular network has emerged as powerful tool allowing metabolism study through organization and representation of untargeted tandem mass spectrometry (MS/MS) data in a graphical form. The aim of this study is to investigate amanitin metabolism using molecular networking. In vivo (four positive amanitin urine samples) and in vitro (differentiated HepaRG cells supernatant incubated with $\alpha$-amanitin $2 \mu \mathrm{M}$ for $24 \mathrm{~h}$ ) samples were extracted and analyzed by LC-HRMS/MS using a $\mathrm{Q}$ Exactive $^{\mathrm{TM}}$ Orbitrap mass spectrometer. Using molecular networking on both in vitro and in vivo, we have demonstrated that $\alpha$-amanitin does not undergo metabolism in human. Thus, we provide solid evidence that a possible production of amanitin metabolites cannot be involved in its toxicity pathways. These findings can help to settle the debate on amanitin metabolism and toxicity.
\end{abstract}

Keyworks : $\alpha$-amanitin, amatoxin, metabolism, HepaRG cells, in vivo, molecular network 


\section{Introduction}

Amanitin poisonings are among the most life-threatening mushroom poisonings, and are mainly caused by the genus Amanita (Broussard, 2001; Vetter, 1998). Hepatotoxicity is the hallmark of amanitins, powerful toxins contained in these mushrooms, and can require liver transplant. Amanitins are bicyclic octapeptides with high molecular weight, great heat stability, and solubility in water, making them extremely resistant to cooking and drying (Wieland et al., 1978). Moreover, amanitins are resistant to enzyme and acid degradation, leading to resistance to gastrointestinal inactivation (Garcia et al., 2015; Wieland et al., 1978). Among amatoxins, $\alpha$-amanitin is the most studied. Its hepatotoxic action follows several well-described key steps. After $\alpha$-amanitin accumulation in the liver via OATP1B3 and $\mathrm{Na}^{+}-$ taurocholate cotransporting polypeptide (NTCP) uptake in the sinusoidal membrane of hepatocytes (Letschert et al., 2006), the main toxic mechanism is attributed to non-covalent binding to RNA polymerase II (RNAP II) in the nucleus, resulting in inhibition of mRNA and protein synthesis (Wieland, 2009). For many years, the amanitin metabolism hypothesis has been recurrent in the literature (Schneider et al., 1992; Thiel et al., 2011; Tong et al., 2007), despite other authors suggesting a lack of metabolism (Garcia et al., 2015). No evidence has been provided to support any of these assumptions so far. A need of clarification using cutting-edge tools allowing metabolism study appears to be necessary.

Molecular networking has emerged as a powerful tool for metabolism studies allowing organization and representation of untargeted tandem mass spectrometry (MS/MS) data in a graphical form (Wang et al., 2016). Each molecular entity represents an ion and its associated fragmentation spectrum, and the links between the nodes indicate similarities between spectra. By propagating structural information within the network and facilitating sample-to-sample comparison, the molecular networking approach offers valuable insights into drug metabolism (Allard et al., 2020, 2019; Le Daré et al., 2019). In addition, molecular networking has recently proven its relevance in in vitro drug metabolism study (Le Daré et al., 2020). In this context, investigating amanitin metabolism could be of particular interest in toxicodynamic understanding and therapeutic development perspective. Therefore, the aim of this study is to investigate hepatotoxic toxin amanitin metabolism using molecular networking.

\section{Materials and methods}

\section{Cell cultures}

Progenitor HepaRG cells were cultured as previously described (Aninat et al., 2006). Briefly, HepaRG cells were seeded at a density of $2.6 \times 10^{4}$ cells $/ \mathrm{cm}^{2}$ in a 8 chamber coverglass Lab-Tek system (Nalge Nunc, Germany) in William's E medium supplemented with $10 \% \mathrm{FBS}, 50 \mathrm{U} / \mathrm{mL}$ penicillin, $50 \mu \mathrm{g} / \mathrm{mL}$ streptomycin, $5 \mu \mathrm{g} / \mathrm{mL}$ insulin, $2 \mathrm{mM}$ glutamine, and $50 \mu \mathrm{M}$ sodium hydrocortisone hemisuccinate. After 2 weeks, cells were cultured in the same medium supplemented with $2 \%$ DMSO for an additional two weeks, in order to induce cell differentiation (into cholangiocyte- and hepatocyte like cells) and expression of liver specific functions such as metabolism enzymes (Cerec et al., 2007). Cells were then treated 24 hours with compounds in $1.7 \%$ DMSO culture medium. $\alpha$-amanitin (purity $\geq 90 \%$ ) were obtained from Sigma-Aldrich (Saint Louis, MO USA).

\section{Cell viability}

Cytotoxicity was assessed using the Luminescent ATP Detection Assay Kit (Abcam, Cambridge, MA, USA) and plates were read by a microplate reader (POLARstar Omega ${ }^{\circledR}$, BMG labtech $^{\circledR}$, Ortenberg, Germany). 


\section{Immunocytofluorescence and cell microscopy}

After exposure to compounds, cells were fixed in paraformaldehyde $4 \%$ and washed with PBS. Anti TOM22 antibody was used at 1:1000. Rhodamine phalloidin (Molecular Probes) was used at 1:500. Anti-rabbit Alexa 488 (Thermo Scientific, San Jose, CA) was used at 1:2000. Nuclei were stained with DAPI $5 \mu \mathrm{g} / \mathrm{mL}$ (Thermo Scientific, San Jose, CA). Images were acquired with a Deltavision inverted widefield microscope using a 20X APO objective (Cytiva Lifescience, Marlborough, MA ,USA).

\section{Amanitin quantitation in human sample}

Four urine samples were collected from suspected amanitin-intoxicated patients at the Rennes University Hospital. Urinary amanitin toxin concentration was measured by LC-HRMS as already described (Gicquel et al., 2014).

\section{Sample preparations}

In vivo samples $(500 \mu \mathrm{L}$ of patient urine) were supplemented with internal standard $(20 \mathrm{ng} / \mathrm{mL}$ virginiamycin in the final vial) and extracted by solid phase extraction (SPE) as already described (Gicquel et al., 2014). In vitro samples ( $25 \mu \mathrm{L}$ of HepaRG cells supernatant) were extracted with $75 \mu \mathrm{L}$ of methanol. The supernatant $(50 \mu \mathrm{L})$ was then diluted with LC-MS grade water $(50 \mu \mathrm{L})$ and transferred into chromatographic vials for LC-HRMS analysis.

\section{LC-HRMS settings}

Liquid chromatography-mass spectrometry (LC-MS) analyses were carried out using Orbitrap Q Exactive $^{\mathrm{TM}}$ mass spectrometer coupled to an UltiMate 3000 pump (Thermo Scientific, San Jose, CA).

Data acquisition, calibration and instrument control were performed using Xcalibur ${ }^{\circledR} 2.1$ (Thermo Scientific) software. Samples were maintained at $15{ }^{\circ} \mathrm{C}$ in the autosampler before analysis.

Chromatographic parameters used were as already described (Le Daré et al., 2020) as follow: The mobile phases were composed of ammonium formiate at $2 \mathrm{mM}$ and formic acid $0.1 \%$ in water (phase A) and ammonium formiate at $2 \mathrm{mM}$ and formic acid $0.1 \%$ in methanol and acetonitrile (50/50) (phase B). LC was performed on a Accucore Phenyl Hexyl $(100 \times 2.1 \mathrm{~mm}, 2.6 \mu \mathrm{m})($ Thermo Scientific, San Jose, CA) using the following gradient elution: initial conditions of 99:1 (A:B) maintained for 1 min, increasing to 1:99 (A:B) for $9 \mathrm{~min}$, followed by a $1.5 \mathrm{~min}$ plateau with 1:99 (A:B) and return to initial conditions 99:1 (A:B) for equilibration. This corresponded to a total chromatographic run of $15 \mathrm{~min}$. The flow rate was $500 \mu \mathrm{L} / \mathrm{min}$, the column temperature was maintained at $40{ }^{\circ} \mathrm{C}$, the injection volume was $20 \mu \mathrm{L}$.

The MS conditions were as follows: heated electrospray ionization source (HESI-II) in the ESI positive mode, capillary temperature: $300^{\circ} \mathrm{C}$; spray voltage: $3,500 \mathrm{~V}$; sheath and auxiliary gas (nitrogen) flow rate: 40 psi and 10 (arbitrary units), respectively. Data are acquired in data-dependant acquisition mode, the range for acquisition was 350-1200 $\mathrm{m} / \mathrm{z}$. Ion precursor selection was performed where the most intense ion from the previous scan was selected for fragmentation. Full scan (MS1) data were acquired at a resolution of 35,000 FWHM, with an AGC target of $1 \mathrm{e} 6$ and a maximum injection time of $120 \mathrm{~ms}$. Source parameters were as follows: source voltage $+3.0 \mathrm{kV}$, sheath gas flow 60 units, auxiliary gas flow 10 units, capillary temperature $320^{\circ} \mathrm{C}, \mathrm{S}$-Lens RF level 60 units. MS/MS (MS2) data were acquired at a resolution of 17,500 FWHM with an AGC target of 1e5, maximum injection time was $50 \mathrm{~ms}$, a TopN of 5 , an isolation window of $2.0 \mathrm{~m} / \mathrm{z}$. The normalized collision energy (NCE) was stepped at 17.5, 35 and 52.5, and the dynamic exclusion time set at $3 \mathrm{~s}$.

A list of possible metabolites was established using GLORY, a freely available generator of the structures of likely cytochrome P450 metabolites based on predicted sites of metabolism (de Bruyn Kops 
et al., 2019) and an inclusion list containing $\alpha$-amanitin and possible metabolites was added in the method.

\section{Molecular networking generation}

Spectral data allowed us to generate MN using semi-quantitative bioinformatics approach. Data acquisition, processing (i.e. MS data conversion, preprocessing, MS1 annotation), visualization and network analysis have been described in detail elsewhere (Allard et al., 2019). In Global Natural Products Social networking (GNPS) web-based platform, the basic parameters were modified to $\mathrm{m} / \mathrm{z}$ 0.02 for the mass tolerance of precursor and fragment ions used for MS/MS spectral library searching, and $\mathrm{m} / \mathrm{z}_{0.02}$ for the mass tolerance of fragment ions used for MN. The minimum cluster size was set to 1. In addition, links between nodes were created when the cosine score was greater than 0.60 , and the minimum number of common fragment ions shared by two MS/MS spectra was 5. Links between two nodes were only kept in the network if each node was in the top 10 most similar nodes. Full data processed through the GNPS platform are accessible through these links:

- https://gnps.ucsd.edu/ProteoSAFe/status.jsp?task=f2530c745f0745c79467a93e28e126a7 (Fig 2)

- https://gnps.ucsd.edu/ProteoSAFe/status.jsp?task=2bacadd3638f4d8d93a6223e3fec1b62 (Fig 3)

The molecular network was visualized using Cytoscape 3.5.1 software (Shannon, 2003). The nodes were annotated by comparison with reference standard, by spectral matching with the GNPS, mzCloud online mass spectral libraries and information propagation (HighChem LLC, 2019).

\section{Statistical analysis}

Cell viability data were expressed as the mean \pm standard error of the mean (SEM). Intergroup differences as a function of the treatment were probed in a one-way analysis of variance (ANOVA), with a Tukey post hoc test for group comparisons. All analyses were performed using Prism software (version 5.0, GraphPad Software, La Jolla, CA, USA). All tests were two-sided, and the threshold for statistical significance was set to $p<0.05$.

\section{Results}

In order to study in vitro $\alpha$-amanitin metabolism, we have chosen a metabolically competent liver model: differentiated HepaRG cells. These cells have already shown valuable relevance in in vitro metabolism study using molecular networking (Le Daré et al., 2020). We first evaluated differentiated HepaRG model consistency by exposing these cells to $\alpha$-amanitin $(0$ to $20 \mu \mathrm{M})$ and cell viability was measured at $24 \mathrm{~h}$ (Figure 1b). 
a.

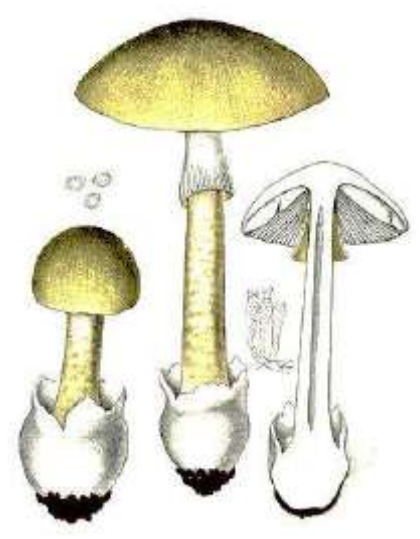

C.

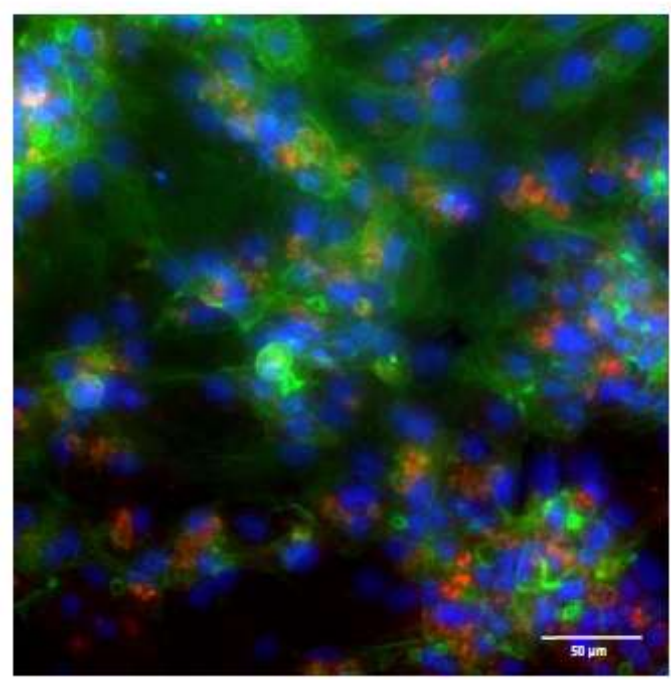

b.

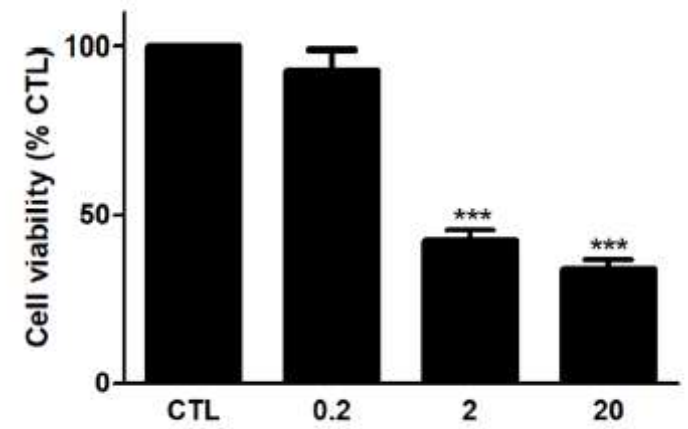

d.

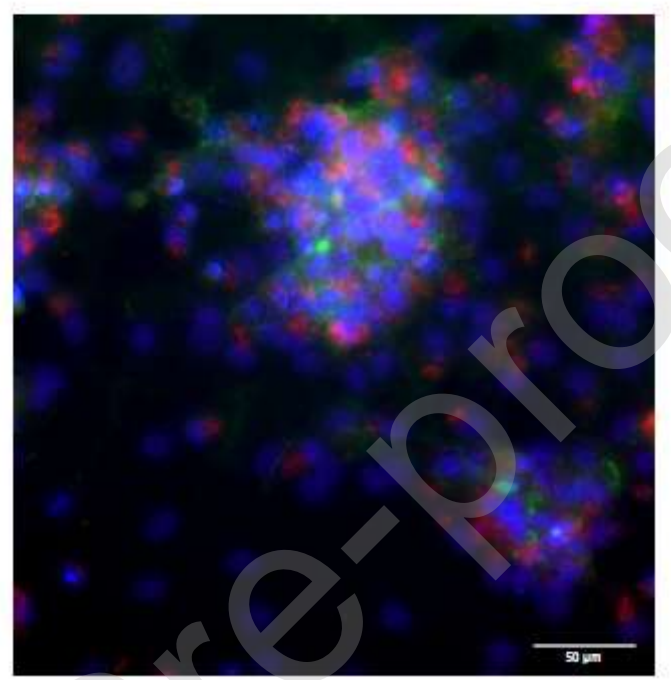

Figure 1: Effect of $\boldsymbol{\alpha}$-amanitin on differentiated HepaRG cells viability. $\boldsymbol{\alpha}$-amanitin $(0$ to $20 \mu \mathrm{M})$ or medium were incubated during $24 \mathrm{~h}$ on differentiated HepaRG cells. a. Representation of an Amanita phalloides (from wikimedia commons) b. Cell viability was measured by an extracellular ATP assay and expressed relative to the value determined after medium treatment alone (arbitrary set to 100\%). The data are quoted as the mean \pm SEM from three independent experiments performed in triplicate. $* * * p<0.001: \alpha$-amanitin condition compared to control condition. $\mathbf{c}$. and d. Cells were labeled with antibodies against TOM22 (mitochondria in red), actin stained with Rhodamine phalloidin (in green) and DAPI nuclei staining (blue) and images were captured with a Deltavision microscope at 20X.c. Differentiated HepaRG incubated with culture media during 24h. d. HepaRG incubated with $\alpha$-amanitin $2 \mu \mathrm{M}$ during $24 \mathrm{~h}$ showing a disorganization of actin fibers (in green) and large aggregates of mitochondria (in red) close to the nucleus compared to control condition, highlighting cellular entry of $\alpha$-amanitin.

Significant decrease in cell viability was observed from $2 \mu \mathrm{M}$ to $20 \mu \mathrm{M} \alpha$-amanitin, in a dose-dependent manner (Figure 1b). Since the $2 \mu \mathrm{M}$ concentration corresponded to approximately $50 \%$ of cells death, it was used for further experiments. Differentiated HepaRG cells sensitivity to amanitin $(2 \mu \mathrm{M})$ was confirmed using fluorescence microscopy, showing a disorganization of actin fibers (in green) compared to control condition. This cytoskeletal toxicity induces a reorganization of the mitochondrial network, as shown in figure $2 \mathrm{~d}$. Compared to control conditions (Figure 1c), cells exposed to $\alpha$-amanitin $(2 \mu \mathrm{M}$ ) show large aggregates of mitochondria close to the nucleus (Figure 1d). These results show that differentiated HepaRG cells are sensitive to this toxin, and thus allow $\alpha$-amanitin to enter into the cells. This revealed that this model is consistent for amanitin metabolism study. 
We then incubated $\alpha$-amanitin $(2 \mu \mathrm{M})$ in differentiated HepaRG cells during $24 \mathrm{~h}$. Culture media analysis allowed us to generate a molecular network from MS/MS data (Figure 2a). Given that the most likely biotransformation reactions predicted using GLORY involved methylation, hydroxylation, carboxylation, glucuronidation and sulfation, (giving rise to $\mathrm{m} / \mathrm{z} 933.379, \mathrm{~m} / \mathrm{z} 935.359, \mathrm{~m} / \mathrm{z} 949.338, \mathrm{~m} / \mathrm{z}$ 1095.396 and $\mathrm{m} / z$ 999.320, respectively), we used an inclusion list in the analytical method. Nodes can be linked together according to their $\mathrm{MS}^{2}$ spectra similarities. Molecular network visual analysis detected an isolated node corresponding to $\alpha$-amanitin $(m / z$ 919.364), without any other related node, suggesting that no $\alpha$-amanitin metabolites could be detected (Figure $2 b$ ). In addition, none of the predicted metabolites were found throughout the molecular network.

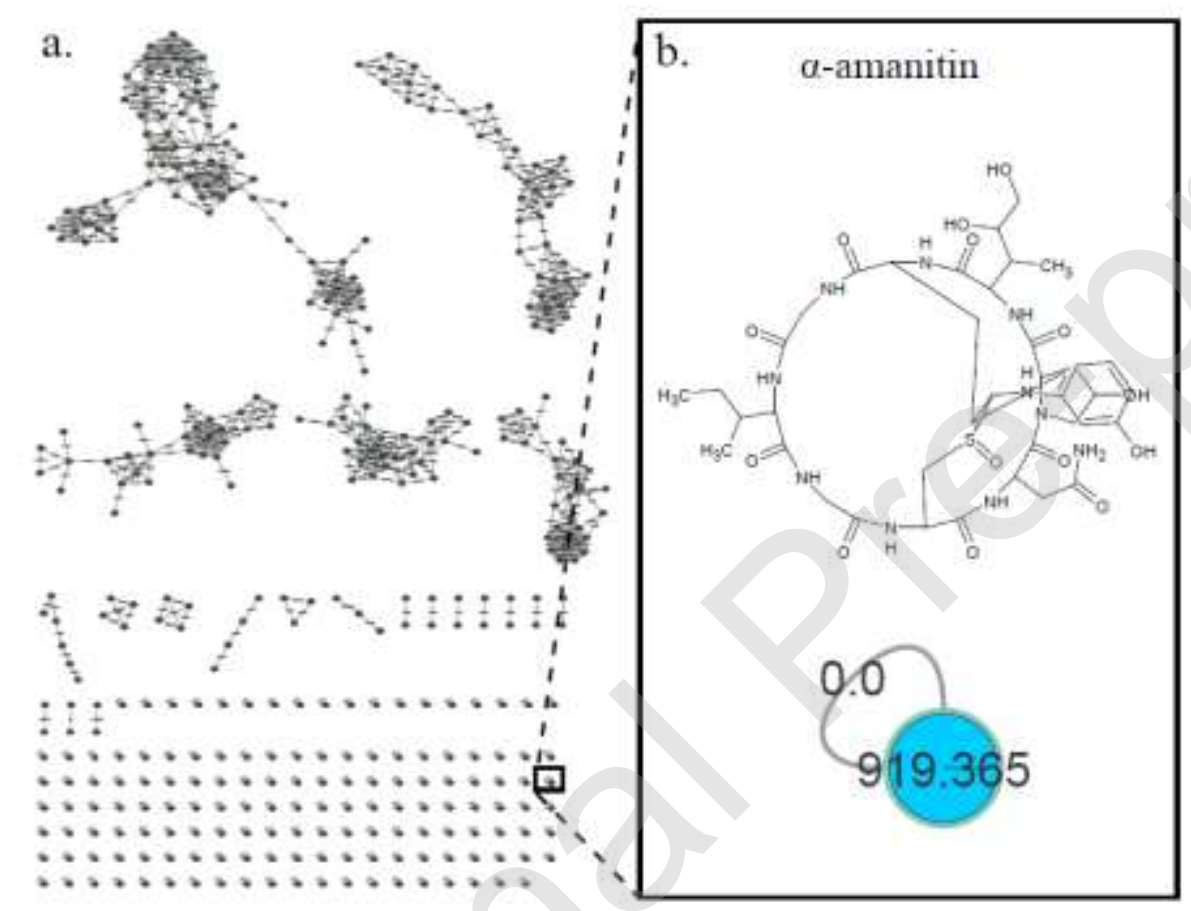

Figure 2: In vitro $\alpha$-amanitin metabolism study using molecular networking. a. Entire molecular network showing all the chemical entities detected using LC-HR-MS/MS. b. $\alpha$-amanitin isolated node

To further investigate amanitin metabolism hypothesis, four urine samples of amanitin intoxicated patients were analyzed. Amanitin intoxication was confirmed using LC-HRMS, showing different $\alpha$ amanitin concentrations: $33.4 \mu \mathrm{g} / \mathrm{g}$ of creatinine (patient 1), $16.1 \mu \mathrm{g} / \mathrm{g}$ of creatinine (patient 2), 68.83 $\mu \mathrm{g} / \mathrm{g}$ of creatinine (patient 3 ) and $7.21 \mu \mathrm{g} / \mathrm{g}$ of creatinine (patient 4). Urine samples analysis generated a multi-matrix molecular network from MS/MS data (Figure 3a). 
a.

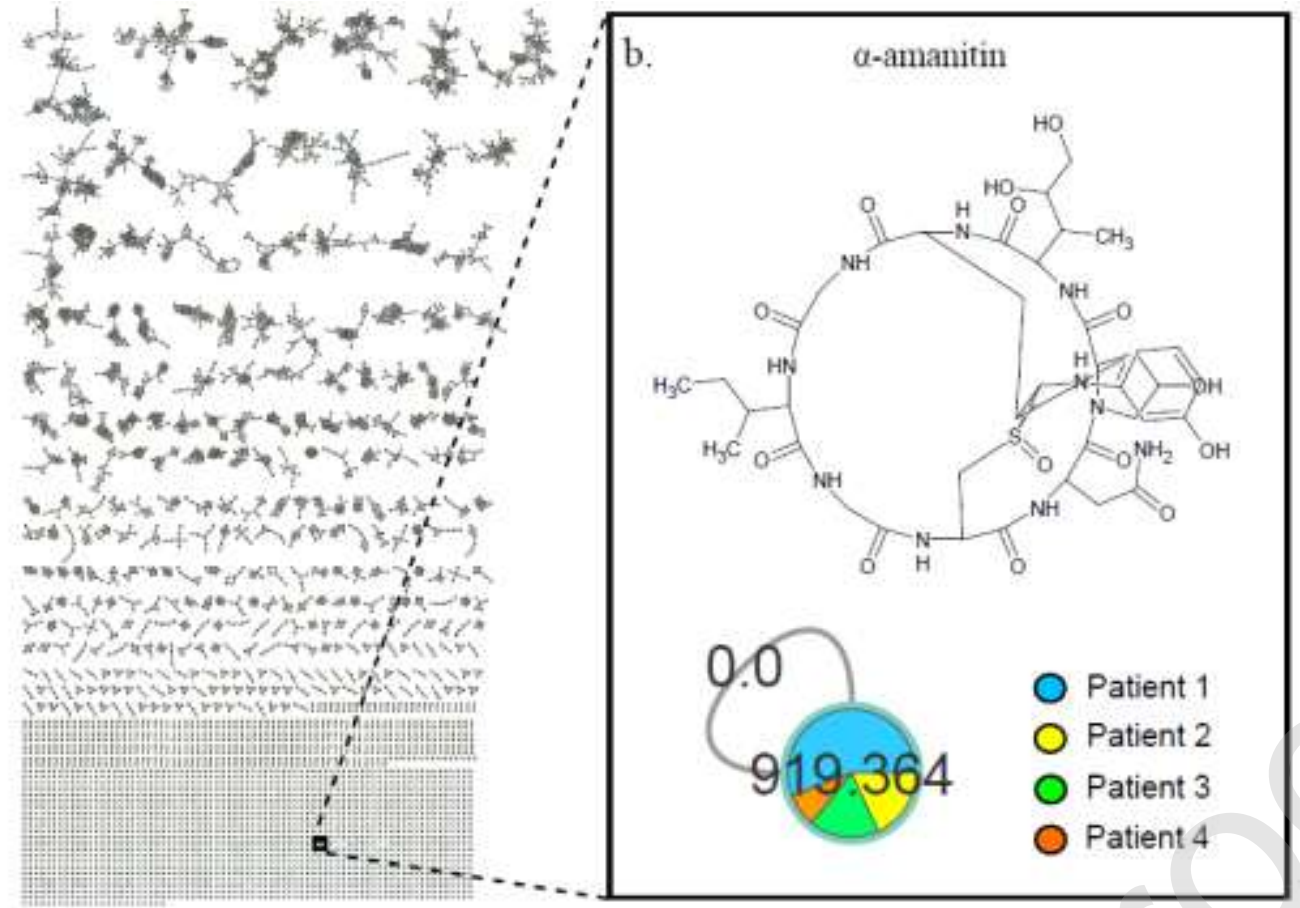

Figure 3: In vivo $\alpha$-amanitin metabolism exploration using molecular networking. a. Entire molecular network showing all the chemical entities detected using LC-HR-MS/MS. b. $\alpha$-amanitin isolated node

A specific color is assigned to each patient (Figure 3b). Visual analysis of the global molecular network from urines showed a much more complex composition in urine samples than in cell culture supernatant. Among all the chemical entities, an isolated node corresponding to $\alpha$-amanitin $(\mathrm{m} / \mathrm{z}$ 919.364) without any related node or predicted metabolites were detected, confirming our in vitro findings (Figure 3b). In addition, no other amatoxins (namely $\gamma$-amanitin $(\mathrm{m} / \mathrm{z}$ 903.3670), $\varepsilon$-amanitin $(\mathrm{m} / \mathrm{z}$ 904.3510), amanin ( $\mathrm{m} / \mathrm{z}$ 904.3510), amanullic acid $(\mathrm{m} / \mathrm{z}, 888.3561)$ and proamanullin $(\mathrm{m} / \mathrm{z} 871.3772))$ were found within the molecular network. Taken together, these results provide new information suggesting that $\alpha$-amanitin does not undergo metabolism.

\section{Discussion}

A possible $\alpha$-amanitin metabolism mentioned in the literature needs to be clarified using an efficient tool to explore $\alpha$-amanitin metabolism as molecular networking.

Our first aim was to validate an experimental model appropriate to in vitro $\alpha$-amanitin metabolism study. HepaRG cells is a bipotent cell line that can differentiate into either cholangiocyte- or hepatocyte-like cells in appropriate culture conditions (Cerec et al., 2007). In addition, differentiated hepatocyte-like HepaRG transcribe liver-specific genes closer to primary human hepatocytes and human liver tissue than any other liver cell lines (Hart et al., 2010; Hugbart et al., 2020). Particularly, Kotani et al. (2012) have shown that differentiated HepaRG cells exhibit OATP1B3 and NTCP expression for amanitin transportation, making it highly likely that amanitin will enter the cells (Kotani et al., 2012). 
Consistently, our results showed that $\alpha$-amanitin exposure of differentiated HepaRG cells induce cell death and cytoskeletal modification at concentrations traditionally used in literature (Magdalan et al., 2011, 2009). Moreover, HepaRG cells express most of the drug processing genes including major CYPs (Aninat et al., 2006) and UGTs (Hugbart et al., 2020; Quesnot et al., 2018), and exhibit a long-term fonctional stability while primary human hepatocyte loose their drug metabolism capacity over time. Thus differentiated HepaRG culture appears as a particularly relevant cell model system for drug metabolism study in our context.

Molecular networking was initially developped to analyse complex natural product mixtures and has proven its relevance in metabolomics (Allard et al., 2017), in dereplication of naturally produced substances (Allard et al., 2016), in toxic plant intoxication cases (Allard et al., 2020), and in drug metabolism for in vivo clinical or forensic purposes (Allard et al., 2019; Le Daré et al., 2019). Moreover, the consistency of molecular networking for in vitro metabolism study using differentiated HepaRG cells has recently been demonstrated (Le Daré et al., 2020). Thus, putative $\alpha$-amanitin metabolites would have been detected using this bioinformatic tool but no metabolite could be identified either in vitro or in vivo, showing that $\alpha$-amanitin does not presumably undergo metabolism in humans.

However, the findings of this study must be interpreted and understood within several limitations. First, the formation of metabolites remaining intracellularly and forming adducts preventing their detection cannot be excluded. Second, it is possible that metabolites formation or other amatoxin concentrations is too low to allow detection with the tools used in our experiments. Third, the question of other forms of metabolism remains legitimate and relevant, particularly through the intestinal microbiota (Colotti and Rinaldi, 2020; Swanson, 2015). However, either these possible compounds are eliminated directly by the fecal route without being absorbed, thus constituting a minor concern for the problem of amanitininduced hepatotoxicity. Either these compounds are absorbed and would most likely be eliminated in the urine due to their water solubility, where they would have been detected in the patients' urine. Fourth, the chromatographic separation and/or mass spectrometric detection might have been unsuitable for some metabolites. Lastly, we can't exclude that metabolites could have been lost or degraded during the workup of the samples. Although these limitations have to be kept in mind to conclude about our present study, we provide new arguments toward the absence of $\alpha$-amanitin metabolism through usual enzymatic biotransformation pathways. As metabolism may be responsible for the toxicity of xenobiotics, the clinical implications are important for the development of effective antidotes (Shehu et al., 2017). In the case of amanitin poisoning, the search for effective therapeutics must therefore focus on mechanisms other than metabolism such as limiting the entry of toxins into the cell, increasing its elimination, or countering oxidative stress.

\section{Declaration of interests}


$\bigotimes$ The authors declare that they have no known competing financial interests or personal relationships that could have appeared to influence the work reported in this paper.

\section{Conflict of Interest Statement}

The authors declare that there is no conflict of interest.

\section{Ethical approval}

Ethical approval ( $\left.{ }^{\circ} 20.116\right)$ was waived by the local Ethics Committee of Rennes University Hospital in view of the retrospective nature of the study and all the procedures being performed were part of the routine care.

\section{REFERENCES}

Allard, P.-M., Genta-Jouve, G., Wolfender, J.-L., 2017. Deep metabolome annotation in natural products research: towards a virtuous cycle in metabolite identification. Curr. Opin. Chem. Biol. 36, 40-49. https://doi.org/10.1016/j.cbpa.2016.12.022

Allard, P.-M., Péresse, T., Bisson, J., Gindro, K., Marcourt, L., Pham, V.C., Roussi, F., Litaudon, M., Wolfender, J.-L., 2016. Integration of Molecular Networking and In-Silico MS/MS Fragmentation for Natural Products Dereplication. Anal. Chem. 88, 3317-3323. https://doi.org/10.1021/acs.analchem.5b04804

Allard, S., Allard, P., Morel, I., Gicquel, T., 2019. Application of a molecular networking approach for clinical and forensic toxicology exemplified in three cases involving 3- MeO- PCP, doxylamine, and chlormequat. Drug Test. Anal. 11, 669-677. https://doi.org/10.1002/dta.2550

Allard, S., Le Daré, B., Allard, P.-M., Morel, I., Gicquel, T., 2020. Comparative molecular networking analysis of a Rauwolfia plant powder and biological matrices in a fatal ingestion case. Forensic Toxicol. https://doi.org/10.1007/s11419-02000531-0

Aninat, C., Piton, A., Glaise, D., Le Charpentier, T., Langouët, S., Morel, F., Guguen-Guillouzo, C., Guillouzo, A., 2006. Expression of cytochromes P450, conjugating enzymes and nuclear receptors in human hepatoma HepaRG cells. Drug Metab. Dispos. Biol. Fate Chem. 34, 75-83. https://doi.org/10.1124/dmd.105.006759

Broussard, C., 2001. Mushroom poisoning - from diarrhea to liver transplantation. Am. J. Gastroenterol. 96, 3195-3198. https://doi.org/10.1016/S0002-9270(01)03845-X

Cerec, V., Glaise, D., Garnier, D., Morosan, S., Turlin, B., Drenou, B., Gripon, P., Kremsdorf, D., Guguen-Guillouzo, C., Corlu, A., 2007. Transdifferentiation of hepatocyte-like cells from the human hepatoma HepaRG cell line through bipotent progenitor. Hepatology 45, 957-967. https://doi.org/10.1002/hep.21536

Colotti, G., Rinaldi, T., 2020. The central role of gut microbiota in drug metabolism and personalized medicine. Future Med. Chem. 12, 1197-1200. https://doi.org/10.4155/fmc-2020-0023

de Bruyn Kops, C., Stork, C., Šícho, M., Kochev, N., Svozil, D., Jeliazkova, N., Kirchmair, J., 2019. GLORY: Generator of the Structures of Likely Cytochrome P450 Metabolites Based on Predicted Sites of Metabolism. Front. Chem. 7, 402. https://doi.org/10.3389/fchem.2019.00402

Garcia, J., Costa, V.M., Carvalho, A., Baptista, P., de Pinho, P.G., de Lourdes Bastos, M., Carvalho, F., 2015. Amanita phalloides poisoning: Mechanisms of toxicity and treatment. Food Chem. Toxicol. 86, 41-55. https://doi.org/10.1016/j.fct.2015.09.008

Gicquel, T., Lepage, S., Fradin, M., Tribut, O., Duretz, B., Morel, I., 2014. Amatoxins ( $\alpha$ - and $\beta$-Amanitin) and Phallotoxin (Phalloidin) Analyses in Urines Using High-Resolution Accurate Mass LC-MS Technology. J. Anal. Toxicol. 38, 335-340. https://doi.org/10.1093/jat/bku035

Hart, S.N., Li, Y., Nakamoto, K., Subileau, E., Steen, D., Zhong, X., 2010. A Comparison of Whole Genome Gene Expression Profiles of HepaRG Cells and HepG2 Cells to Primary Human Hepatocytes and Human Liver Tissues. Drug Metab. Dispos. 38, 988-994. https://doi.org/10.1124/dmd.109.031831

HighChem LLC, 2019. mzCloud - Advanced Mass Spectral Database [WWW Document]. URL https://www.mzcloud.org/ (accessed 11.12.18).

Hugbart, C., Verres, Y., Le Daré, B., Bucher, S., Vène, E., Bodin, A., Lagente, V., Fromenty, B., Bouvet, R., Morel, I., Loyer, P., Gicquel, T., 2020. Non-oxidative ethanol metabolism in human hepatic cells in vitro: Involvement of uridine diphospho-glucuronosyltransferase 1A9 in ethylglucuronide production. Toxicol. In Vitro 66, 104842. https://doi.org/10.1016/j.tiv.2020.104842

Kotani, N., Maeda, K., Debori, Y., Camus, S., Li, R., Chesne, C., Sugiyama, Y., 2012. Expression and Transport Function of Drug Uptake Transporters in Differentiated HepaRG Cells. Mol. Pharm. 9, 3434-3441. https://doi.org/10.1021/mp300171p

Le Daré, B., Allard, S., Bouvet, R., Baert, A., Allard, P.-M., Morel, I., Gicquel, T., 2019. A case of fatal acebutolol poisoning: an illustration of the potential of molecular networking. Int. J. Legal Med. https://doi.org/10.1007/s00414-01902062-9 
Le Daré, B., Ferron, P.-J., Allard, P.-M., Clément, B., Morel, I., Gicquel, T., 2020. New insights into quetiapine metabolism using molecular networking. Sci. Rep. 10, 19921. https://doi.org/10.1038/s41598-020-77106-x

Letschert, K., Faulstich, H., Keller, D., Keppler, D., 2006. Molecular Characterization and Inhibition of Amanitin Uptake into Human Hepatocytes. Toxicol. Sci. 91, 140-149. https://doi.org/10.1093/toxsci/kfj141

Magdalan, J., Ostrowska, A., Podhorska-Okołów, M., Piotrowska, A., Iżykowska, I., Nowak, M., Dolińska-Krajewska, B., Zabel, M., Szeląg, A., Dzięgiel, P., 2009. Early morphological and functional alterations in canine hepatocytes due to $\alpha$-amanitin, a major toxin of Amanita phalloides. Arch. Toxicol. 83, 55-60. https://doi.org/10.1007/s00204-0080376-9

Magdalan, J., Piotrowska, A., Gomułkiewicz, A., Sozański, T., Szeląg, A., Dziegięl, P., 2011. Influence of commonly used clinical antidotes on antioxidant systems in human hepatocyte culture intoxicated with $\alpha$-amanitin. Hum. Exp. Toxicol. 30, 38-43. https://doi.org/10.1177/0960327110368418

Quesnot, N., Bucher, S., Gade, C., Vlach, M., Vene, E., Valença, S., Gicquel, T., Holst, H., Robin, M.-A., Loyer, P., 2018. Production of chlorzoxazone glucuronides via cytochrome P4502E1 dependent and independent pathways in human hepatocytes. Arch. Toxicol. 92, 3077-3091. https://doi.org/10.1007/s00204-018-2300-2

Schneider, S.M., Michelson, E.A., Vanscoy, G., 1992. Failure ofN-Acetylcysteine to reduce alpha amanitin toxicity. J. Appl. Toxicol. 12, 141-142. https://doi.org/10.1002/jat.2550120211

Shannon, P., 2003. Cytoscape: A Software Environment for Integrated Models of Biomolecular Interaction Networks. Genome Res. 13, 2498-2504. https://doi.org/10.1101/gr.1239303

Shehu, A.I., Ma, X., Venkataramanan, R., 2017. Mechanisms of Drug-Induced Hepatotoxicity. Clin. Liver Dis. 21 , 35-54. https://doi.org/10.1016/j.cld.2016.08.002

Swanson, H.I., 2015. Drug Metabolism by the Host and Gut Microbiota: A Partnership or Rivalry? Drug Metab. Dispos. Biol. Fate Chem. 43, 1499-1504. https://doi.org/10.1124/dmd.115.065714

Thiel, C., Thiel, K., Klingert, W., Diewold, A., Scheuermann, K., Hawerkamp, E., Lauber, J., Scheppach, J., Morgalla, M.H., Königsrainer, A., Schenk, M., 2011. The enterohepatic circulation of amanitin: Kinetics and therapeutical implications. Toxicol. Lett. 203, 142-146. https://doi.org/10.1016/j.toxlet.2011.03.016

Tong, T.C., Hernandez, M., Richardson, W.H., Betten, D.P., Favata, M., Riffenburgh, R.H., Clark, R.F., Tanen, D.A., 2007. Comparative Treatment of $\alpha$-Amanitin Poisoning With N-Acetylcysteine, Benzylpenicillin, Cimetidine, Thioctic Acid, and Silybin in a Murine Model. Ann. Emerg. Med. 50, 282-288. https://doi.org/10.1016/j.annemergmed.2006.12.015

Vetter, J., 1998. Toxins of Amanita phalloides. Toxicon 36, 13-24. https://doi.org/10.1016/S0041-0101(97)00074-3

Wang, M., Carver, J.J., Phelan, V.V., Sanchez, L.M., Garg, N., Peng, Y., Nguyen, D.D., Watrous, J., Kapono, C.A., LuzzattoKnaan, T., Porto, C., Bouslimani, A., Melnik, A.V., Meehan, M.J., Liu, W.-T., Crüsemann, M., Boudreau, P.D., Esquenazi, E., Sandoval-Calderón, M., Kersten, R.D., Pace, L.A., Quinn, R.A., Duncan, K.R., Hsu, C.-C., Floros, D.J., Gavilan, R.G., Kleigrewe, K., Northen, T., Dutton, R.J., Parrot, D., Carlson, E.E., Aigle, B., Michelsen, C.F., Jelsbak, L., Sohlenkamp, C., Pevzner, P., Edlund, A., McLean, J., Piel, J., Murphy, B.T., Gerwick, L., Liaw, C.-C., Yang, Y.-L., Humpf, H.-U., Maansson, M., Keyzers, R.A., Sims, A.C., Johnson, A.R., Sidebottom, A.M., Sedio, B.E., Klitgaard, A., Larson, C.B., Boya P, C.A., Torres-Mendoza, D., Gonzalez, D.J., Silva, D.B., Marques, L.M., Demarque, D.P., Pociute, E., O’Neill, E.C., Briand, E., Helfrich, E.J.N., Granatosky, E.A., Glukhov, E., Ryffel, F., Houson, H., Mohimani, H., Kharbush, J.J., Zeng, Y., Vorholt, J.A., Kurita, K.L., Charusanti, P., McPhail, K.L., Nielsen, K.F., Vuong, L., Elfeki, M., Traxler, M.F., Engene, N., Koyama, N., Vining, O.B., Baric, R., Silva, R.R., Mascuch, S.J., Tomasi, S., Jenkins, S., Macherla, V., Hoffman, T., Agarwal, V., Williams, P.G., Dai, J., Neupane, R., Gurr, J., Rodríguez, A.M.C., Lamsa, A., Zhang, C., Dorrestein, K., Duggan, B.M., Almaliti, J., Allard, P.-M., Phapale, P., Nothias, L.-F., Alexandrov, T., Litaudon, M., Wolfender, J.-L., Kyle, J.E., Metz, T.O., Peryea, T., Nguyen, D.-T., VanLeer, D., Shinn, P., Jadhav, A., Müller, R., Waters, K.M., Shi, W., Liu, X., Zhang, L., Knight, R., Jensen, P.R., Palsson, B.Ø., Pogliano, K., Linington, R.G., Gutiérrez, M., Lopes, N.P., Gerwick, W.H., Moore, B.S., Dorrestein, P.C., Bandeira, N., 2016. Sharing and community curation of mass spectrometry data with Global Natural Products Social Molecular Networking. Nat. Biotechnol. 34, 828-837. https://doi.org/10.1038/nbt.3597

Wieland, T., 2009. The toxic peptides from Amanita mushrooms. Int. J. Pept. Protein Res. 22, 257-276. https://doi.org/10.1111/j.1399-3011.1983.tb02093.x

Wieland, T., Faulstich, H., Fiume, L., 1978. Amatoxins, Phallotoxins, Phallolysin, and Antamanide: The Biologically Active Components of Poisonous Amanita Mushroom. CRC Crit. Rev. Biochem. 5, 185-260. https://doi.org/10.3109/10409237809149870 